\title{
DEFESA QUÍMICA: HISTÓRICO, CLASSIFICAÇÃO DOS AGENTES DE GUERRA E AÇÃO DOS NEUROTÓXICOS
}

\author{
Gustavo Rocha Silva, Itamar Borges Jr. e José Daniel Figueroa-Villar*
}

Seção de Química, Instituto Militar de Engenharia, Pça Gal. Tibúrcio, 80, 22290-270 Rio de Janeiro - RJ, Brasil

Alexandre Taschetto de Castro

Centro Tecnológico do Exército, Av. das Américas, 28705, 23020-470 Rio de Janeiro - RJ, Brasil

Recebido em 26/10/11; aceito em 26/7/12; publicado na web em 4/9/12

\begin{abstract}
CHEMICAL DEFENSE: HISTORY, WARFARE AGENT CLASSIFICATION AND ACTION OF NEUROTOXIC AGENTS. Chemical agents are substances used for their toxic effects on humans, animals and plants. The main objective of chemical defense is to develop systems that reduce these effects while minimizing impact on the operational capacity of military troops. In this work, a report on the development of chemical warfare agents since the First World War and their classification is presented. Special attention is given to neurotoxic agents, the most lethal group of chemical agents known to date.
\end{abstract}

Keywords: chemical defense; warfare agents; neurotoxic agents.

\section{INTRODUÇÃO}

Segundo a Organização Mundial de Saúde (OMS), agentes químicos de guerra são substâncias empregadas por causa dos efeitos tóxicos provocados em homens, animais e plantas. ${ }^{1}$ A experiência de duas grandes guerras e o aperfeiçoamento que os agentes químicos de guerra tiveram, assim como seus processos de lançamento e utilização, situam a Guerra Química como uma das formas mais letais de atividade bélica, ainda que proibidas pela Organização das Nações Unidas (ONU). Para estas substâncias três grandes aplicações lhe são atribuídas: ${ }^{2}$ o emprego contra pessoas e animais por meio de gases; a cobertura ou sinalização pela fumaça em áreas e alvos militares e, a destruição de materiais e ataque a pessoas pelo fogo.

Das três formas de emprego bélico, ressalta-se a primeira, que é o foco deste artigo.

Os agentes químicos têm seu uso citado desde a Antiguidade, porém, foi com o advento da indústria química na segunda metade do século XIX que seu uso como arma poderosa de destruição em massa tornou-se tecnicamente viável.

Em um contexto militar, podem-se mencionar dois objetivos básicos para o uso de armas químicas contra pessoas: ${ }^{2}$ causar baixas (mortos e feridos) nas tropas e diminuir o desempenho operacional das tropas inimigas, em razão da necessidade do uso prolongado de equipamentos de proteção.

Juntamente com as armas nucleares e biológicas, as armas químicas formam o grupo das armas não convencionais, que causam um número de baixas muito maior que as armas convencionais, baseadas em explosivos. Uma estimativa para o custo de uma operação em larga escala com armas convencionais empregadas contra uma população civil é de US\$2.000 por $\mathrm{km}^{2}$. Para armas nucleares o custo baixa para US\$ 800; para armas químicas, US\$ 600, e para armas biológicas, US\$ 1. Como o custo das armas químicas e biológicas é menor do que o das armas nucleares, as primeiras foram chamadas de "bomba atômica dos pobres". 3

As armas químicas ganharam importância militar na Primeira Guerra Mundial, quando em 1915, o exército alemão utilizou gás cloro contra tropas aliadas na Bélgica. Porém, foi somente na Segunda Guerra Mundial que se desenvolveram os mais potentes agentes

*e-mail: figueroa@ime.eb.br químicos de guerra, os chamados organofosforados neurotóxicos, ou "agentes dos nervos". Estes agentes possuem toxicidade várias vezes maior do que seus similares conhecidos até então e que foram inicialmente planejados como pesticidas. ${ }^{4}$ Nas últimas décadas, devido ao baixo custo e fácil manufatura, os organofosforados passaram a ser alvo de interesse de organizações terroristas, ${ }^{5}$ fazendo com que a defesa contra tais agentes passasse a ser um foco de preocupação tanto no meio militar quanto civil..$^{6,7}$

Todos os agentes neurotóxicos, agentes de guerra química e pesticidas organofosforados possuem um átomo de fósforo quiral, que leva à formação de um par de isômeros em proporções iguais. O fundamento principal da toxicidade dos agentes neurotóxicos está na inibição da enzima acetilcolinesterase, que participa de forma fundamental na terminação do processo de transmissão dos impulsos nervosos em várias estruturas do corpo humano.

Atualmente, são realizadas pesquisas em defesa contra armas químicas tanto na área de detecção, com o desenvolvimento de novos biossensores, ${ }^{8}$ como na área de proteção, com o surgimento de novas tecnologias para os equipamentos de proteção. ${ }^{9}$ Porém, é no nível do tratamento médico que se concentra a maior parte do esforço, especificamente, no caso dos neurotóxicos, no desenvolvimento de novos fármacos para serem usados no pré-tratamento (como os carbamatos) e antídotos (oximas).

Apesar do esforço dispendido, atualmente ainda não existe nenhum fármaco totalmente eficaz contra todos os agentes neurotóxicos. Em geral, o tratamento para intoxicação com organofosforados neurotóxicos é feito em várias etapas. ${ }^{10,11}$ Dependendo do grau de intoxicação e do tempo de exposição, os antídotos disponíveis podem não apresentar resposta adequada, o que pode levar a graves danos irreversíveis ou à morte da vítima.

A pesquisa sobre antídotos para agentes fosforados neurotóxicos também é de interesse civil em função do grande uso de agroquímicos organofosforados, o que ocasiona muitos casos de intoxicação em agricultores. Estima-se que a exposição acidental a pesticidas organofosforados seja de aproximadamente um milhão de casos anuais, com a maior ocorrência em países subdesenvolvidos. ${ }^{12}$

\section{HISTÓRICO DA GUERRA QUÍMICA}

Desde a Antiguidade, existem relatos da utilização de substâncias 
químicas tóxicas como agentes de guerra. Formas primitivas de uso são encontradas em textos de pesquisadores das Idades Antiga e Média. Na América do Sul, os nativos utilizavam o curare, um anestésico muscular extraído da pele de rãs, para a caça, bem como em guerras contra tribos rivais. Um exemplo curioso dos nativos brasileiros foi a utilização do "gás pimenta" pelos índios da província de Pernambuco. Eles aguardavam soprar um vento favorável, para então fazer uma fogueira na qual colocavam grandes quantidades de pimenta em cima. A fumaça desprendida, altamente irritante aos olhos, penetrava as fortificações da época e fazia com que os soldados saíssem de seus postos em condições prejudicadas de luta. Assim, o ataque podia ser realizado com mais chances de sucesso. Estas situações tiveram lugar no século XVI. ${ }^{13}$ Mais tarde, um dos agentes lacrimogênios mais comuns, a cloroacetofenona $\left(\mathrm{ClCH}_{2} \mathrm{COC}_{6} \mathrm{H}_{5}\right)$, ganhou o nome também de "gás pimenta". Naturalmente, a substância química não é a mesma aplicada pelos nativos da época da colonização, porém a forma de ação é a mesma.

No final do século XIX, a polícia francesa fazia uso de outro tipo de agente lacrimogênio, agora baseado em bromoacetato de etila e envasado em granadas de mão. Na mesma época, os alemães experimentaram o brometo de xilila em munições de artilharia. Décadas depois, no começo do século $\mathrm{XX}$, ingleses e americanos haviam desenvolvido a cloroacetofenona $(\mathrm{CN})$, que foi o lacrimogênio mais utilizado até depois da metade daquele século.

As armas químicas ganharam importância militar na Primeira Guerra Mundial quando, em abril de 1915, o exército alemão descarregou 180 t de gás cloro contra tropas aliadas na Bélgica, o que causou 15.000 vítimas, das quais 5.000 fatais. Seguindo uma sugestão de Fritz Haber (Prêmio Nobel de Química em 1918, mais conhecido pelo processo de produção da amônia que leva seu nome), os alemães colocaram aproximadamente 5500 cilindros de cloro em uma linha de $6 \mathrm{~km}$ e esperaram que o vento soprasse em direção às tropas aliadas. Não esperando que o ataque tivesse sucesso, os aliados foram surpreendidos, assim como os alemães, que não possuíam tropas suficientes na área para aproveitar o grande espaço criado nas linhas defensivas aliadas.

A indignação generalizada com a natureza imoral do ataque na Bélgica não foi suficiente para evitar que os aliados traçassem planos imediatos de retaliação com armas químicas, que foram levados a cabo com os mesmos métodos, em setembro de 1915, contra posições alemãs em Loos, na França. A partir deste ponto, a guerra foi marcada pelo advento de técnicas ofensivas e defensivas de ambos os lados. Com a mesma rapidez que máscaras contra gases e novos filtros eram criados, novos agentes químicos, que não fossem retidos pelas máscaras ou que destruíssem o filtro permitindo a passagem de outros mais tóxicos, eram empregados. Deste embate surgiu o emprego militar do fosgênio $\left(\mathrm{COCl}_{2}\right)$, disfogênio $\left(\mathrm{ClCOOCl}_{3}\right)$, cianeto de hidrogênio $(\mathrm{HCN})$ e cloreto de cianogênio $(\mathrm{CNCl})$ como armas de guerra química.

Em dezembro do mesmo ano (1915) foi introduzido efetivamente o gás fosgênio no conflito através de armas de artilharia para tal fim e, em abril de 1917, o gás mostarda $\left(\left(\mathrm{CH}_{2} \mathrm{CH}_{2} \mathrm{Cl}\right)_{2} \mathrm{~S}\right)$. ${ }^{14}$ Ao contrário dos agentes empregados até então, que agiam sobre o sistema respiratório, os gases mostarda causavam queimaduras químicas ao entrar em contato com a pele, ${ }^{15}$ o que forçava a utilização de vestimentas impermeáveis, que diminuíam sensivelmente a operacionalidade de combate da tropa. Estima-se que 120.000 britânicos foram vítimas de ataque com gás mostarda, porém a mortalidade foi considerada baixa, da ordem de 3\%. Devido a sua grande eficiência, o gás mostarda foi o agente químico que mais causou baixas na Primeira Guerra Mundial, que o levou a ser chamado de "Rei dos Gases". Estima-se que ao final da Primeira Guerra Mundial o número de vítimas dos agentes químicos foi cerca de 1,3 milhão, sendo 100 mil mortos ${ }^{16} \mathrm{~A}$ denominação "gás mostarda", às vezes utilizada de forma genérica, é corretamente aplicada à mostarda de enxofre destilada, isto porque na estrutura química apresentada, a mostarda também pode ser derivada do nitrogênio ao invés do enxofre.

Desde 1918 até a Segunda Guerra Mundial, vários casos de uso de agentes químicos nos mais diversos conflitos foram relatados, alguns de difícil comprovação. Os eventos documentados mais importantes foram o uso de gás mostarda na Etiópia pela Itália em 1936, gás mostarda e outros agentes na invasão da China pelo Japão a partir de $1937^{14}$ e outros casos não comprovados nos conflitos da Espanha contra tribos locais no Marrocos e da Rússia contra tribos do Curdistão. ${ }^{10}$

Em 1925 foi assinado o Protocolo de Genebra que previa a proibição do uso, mas não a posse, de armas químicas. O Protocolo só se aplicava aos países signatários e não continha a previsão de sanções para quem o violasse. Além disso, alguns países não o assinaram, como os Estados Unidos, enquanto outros o fizeram com ressalvas. Apesar de bastante limitado, o Protocolo de Genebra foi o primeiro marco na luta pela proibição do uso de armas químicas em nível mundial.

Já durante a Segunda Guerra Mundial houve um retrocesso no uso, mas não no desenvolvimento, de agentes químicos. Apenas um caso de uso de armas químicas foi relatado na Segunda Guerra Mundial, sendo que o mesmo foi um incidente não planejado: em 1943, o porto de Bari, Itália, sofreu um bombardeio alemão que atingiu o navio norte-americano SS John Harvey, ancorado com uma carga de 2.000 munições contendo um agente mostarda. $\mathrm{O}$ incêndio decorrente formou vapores tóxicos que se espalharam pela cidade. Não foi registrado o número de feridos civis, porém entre as tripulações do navio atingido e os demais ancorados, 617 vítimas foram contabilizadas com $14 \%$ de mortalidade. ${ }^{10}$

Apesar de não terem sido efetivamente empregados durante a Segunda Guerra Mundial, foi nesta época que se desenvolveram os mais potentes agentes químicos, com toxicidade várias vezes maior comparados com os já conhecidos e utilizados na Primeira Guerra Mundial: os organofosforados neurotóxicos, conhecidos como "agentes dos nervos" e desenvolvidos pelos alemães. ${ }^{4}$ Grandes quantidades de agentes neurotóxicos foram estocadas pela Alemanha durante este conflito mundial, especificamente entre 10.000 e 30.000 t destas substâncias acondicionadas em munições.

Com o final da Segunda Guerra Mundial surgiu o problema do que fazer com a gigantesca quantidade de agentes químicos capturada pelos aliados. Estas substâncias tiveram os mais diferentes destinos: incineradas, enterradas em minas inundadas, jogadas ao mar ou transportadas para bases de pesquisa aliadas. O lançamento de munições químicas alemãs nas águas relativamente rasas do Mar Báltico gera consequências ambientais até hoje. ${ }^{17}$

Durante o período da Guerra Fria, a pesquisa em armas químicas continuou a ser realizada pelos países da Organização do Tratado do Atlântico Norte (OTAN) e do Pacto de Varsóvia. Estes países acumularam grandes estoques de munições químicas. Especial atenção às armas químicas era dada pela antiga União das Repúblicas Socialistas Soviéticas (URSS) não só na pesquisa, mas também na área de defesa. As forças militares soviéticas possuíam um efetivo estimado de 50 a 100 mil homens especialistas em guerras química, biológica e nuclear, sendo este o maior grupo deste gênero no mundo.

Apesar de terem sido sintetizados na época da Segunda Guerra Mundial, só em 1988 é que se teve o primeiro relato confirmado do uso de um agente de guerra neurotóxico: o agente sarin foi empregado contra os curdos pelo Iraque. ${ }^{18} \mathrm{Em} 1994$, um ataque terrorista pela seita Aum Shinrikyo em Matsumoto, no Japão, utilizou sarin contra civis e acarretou a morte de 7 pessoas com 200 intoxicados que precisaram de cuidados médicos. ${ }^{19} \mathrm{Em} \mathrm{1995,} \mathrm{um} \mathrm{outro} \mathrm{ataque} \mathrm{terrorista}$ 
com sarin pelo mesmo grupo no Japão, agora em Tóquio, provocou 5.000 vítimas, sendo 12 fatais imediatamente e várias outras ao longo de alguns anos. ${ }^{20-22}$ Em 1996, o governo dos Estados Unidos reconheceu que suas tropas poderiam ter sido expostas ao sarin durante a Guerra do Golfo, em 1991.23 Isto teria ocorrido durante a destruição de um depósito de armas químicas em Khamisiyah, Iraque. ${ }^{24}$ Sob o pretexto da possível existência de depósitos de armas químicas pelo governo de Sadam Houssein no Iraque, os Estados Unidos, apoiados pela Inglaterra, em desacordo com resoluções da ONU, invadiram o Iraque em 2003.

Esses fatos mostram que a utilização desse tipo de arma continua a representar uma ameaça iminente à segurança de qualquer país, seja ela interna ou externa. Liderada pela Organização para Proibição de Armas Químicas (OPAQ), a Convenção de Proibição de Armas Químicas (CPAQ), assinada em 1993 em Paris e em vigor desde 1997, proíbe o desenvolvimento, produção, estocagem e uso de armas químicas bem como promove a eliminação de estoques existentes de tais armas. ${ }^{25}$ Porém até hoje existem vários países que não assinaram esse documento. O Brasil, por sua vez, assinou a convenção no dia da sua abertura, em 1993.

Devido ao baixo custo e à facilidade de manufatura, as armas químicas passaram do interesse estritamente militar para o interesse de organizações terroristas. ${ }^{5}$ Isto faz com que a defesa contra tais agentes, a chamada defesa contra guerra química, deixe de ser um objeto de preocupação essencialmente militar e se torne uma preocupação também do âmbito civil.

\section{DEFESA QUÍMICA}

O principal objetivo da Defesa Química é desenvolver sistemas que minimizem os efeitos tóxicos dos agentes químicos, com um impacto mínimo na capacidade operacional da tropa exposta. ${ }^{26}$ Pode-se, então, destacar três níveis de defesa contra armas químicas: detecção e/ou descontaminação da área exposta ao agente tóxico, evitando contato indireto do mesmo com os indivíduos; proteção individual e/ou coletiva para evitar o contato direto com o agente tóxico, caso seja necessário entrar em uma área exposta e, tratamento médico especializado, caso haja contato com o agente tóxico.

Estas atividades representam uma sobrecarga à atividade operacional das tropas, onde a utilização de equipamentos de proteção individual limita a operacionalidade em geral.

O impacto psicológico provocado pela perspectiva de exposição a um agente químico letal faz com que o treinamento militar deva ser o mais detalhado e especializado possível. Estudos mostram que a exposição aos agentes químicos leva a uma série de respostas psicológicas que incluem perda de memória e concentração, reações esquizofrênicas e depressão. ${ }^{27}$ Em exercícios de treinamento, entre 10 a $20 \%$ dos participantes sofrem de ansiedade, pânico e claustrofobia em função do uso de equipamentos de proteção.

\section{EXPOSIÇÃO ${ }^{27}$}

Quando acontece a exposição ao agente tóxico, a substância química deve vencer barreiras para atingir o sistema circulatório. Este transporte pode ser facilitado por várias características, especialmente a lipofilicidade, facilidade de geração de sprays ou baixo ponto de ebulição.

As formas de absorção dessas substâncias se subdividem em:

- $\quad$ ingestão oral - agente pode ser absorvido por qualquer região do sistema gastrointestinal, dependendo de fatores como tempo de retenção e $\mathrm{pH}$, com maior probabilidade de absorção em áreas específicas, especialmente no intestino delgado, que é o principal órgão de absorção;
- absorção por inalação respiratória, que é a forma mais importante devido à pequena barreira proporcionada pelas células pulmonares, o que permite uma eficiente troca de gases e partículas entre o meio externo e o sistema circulatório. Outro importante fator é o tamanho da partícula, que determina se ela será retida nos cílios ou chegará aos alvéolos;

- absorção cutânea, que é a mais resistente à penetração devido às células epiteliais, cujas membranas são mais espessas e contêm queratina. A via cutânea impede a penetração da maioria das substâncias, com exceção das muito lipossolúveis.

\section{Toxicodinâmica}

A maioria das substâncias tóxicas é específica, ou seja, interage com um só tipo de estrutura-alvo no organismo, sendo os alvos principais as proteínas (enzimas, receptores, proteínas de transporte, etc), os lipídios (membranas celulares) e ácidos nucleicos.

As enzimas catalisam as reações biológicas. O sítio ativo é o local da enzima onde a reação com um determinado substrato se processa. Uma substância química pode dificultar o acesso do substrato ao sítio, seja impedindo sua passagem ou reagindo ela mesma com o sítio. A substância também pode ligar-se à enzima, provocando uma mudança de conformação que impeça seu funcionamento. No caso de receptores, um processo bioquímico é desencadeado pela interação com um ligante, como a liberação de um hormônio ou neurotransmissor. Moléculas com o mesmo efeito do ligante natural são chamadas agonistas, caso contrário, antagonistas. A hemoglobina do sangue tem uma afinidade ao monóxido de carbono duzentas vezes maior do que ao oxigênio, prejudicando assim o transporte do último. Neste caso, o monóxido é um exemplo de antagonista.

As membranas celulares são compostas por uma camada dupla fosfolipídica. Solventes orgânicos e gases muito lipossolúveis dissolvem-se com facilidade nas membranas do sistema nervoso e outros órgãos, alterando a estrutura e prejudicando a função da membrana.

Os nucleotídeos que compõem o DNA são suscetíveis aos ataques de substâncias químicas que interagem com os ácidos nucleicos. O ácido nitroso, por exemplo, pode remover um grupo amino de dois tipos de bases dos nucleotídeos; já o gás mostarda tem o poder de alquilar as bases. Quando a estrutura danificada do DNA não é corrigida pelo organismo e ainda se reproduz, ocorrem mutações que podem provocar o aparecimento de câncer.

\section{CLASSIFICAÇÃO}

A definição de agente químico como qualquer substância química empregada em função de seus efeitos tóxicos diretos no homem, em animais ou plantas ${ }^{1}$ é uma definição muito abrangente. Além de incluir os agentes químicos de alta toxicidade, inclui também os agentes de controle de distúrbios urbanos (cloroacetofenona e lacrimogênios, em geral), herbicidas e toxinas de origem biológica.

Para a Convenção de Proibição de Armas Químicas (CPAQ), agentes controladores de distúrbios urbanos e herbicidas não estão incluídos na lista de armas químicas. Já as toxinas de origem biológica são melhor classificadas como armas biológicas de guerra, sendo tratadas na Convenção de Toxina e Armas Biológicas (BWTC), mas também incluídas na CPAQ. Militarmente, fumígenos e incendiários são também classificados como agentes químicos de guerra, devido à sua importância tática durante um combate. ${ }^{2}$

Os agentes químicos de guerra podem ser classificados quanto ao seu emprego tático, efeito fisiológico e persistência (Tabela 1). Os agentes neurotóxicos, vesicantes, hemotóxicos e sufocantes são causadores de baixas, enquanto que vomitivos e lacrimogênios são classificados como inquietantes (conhecidos mais como 
agentes controladores de distúrbio ou irritantes). Segundo o Exército Brasileiro, apenas os psicoquímicos são enquadrados como agentes incapacitantes. ${ }^{2}$ A linha que separa os agentes causadores de baixas e os incapacitantes é tênue, pois em altas concentrações qualquer agente incapacitante pode causar baixas. Esta distinção é feita através da razão entre a dose incapacitante média $\left(\mathrm{ID}_{50}\right)$ e a dose letal média $\left(\mathrm{LD}_{50}\right)$. Caso esta razão seja inferior a 1/100 o agente é considerado incapacitante. Lembra-se que a $\mathrm{LD}_{50}$ é definida como a dose que leva à morte $50 \%$ dos indivíduos expostos, já a ID $_{50}$ é definida como a dose que incapacita ao combate $50 \%$ dos indivíduos.

Tabela 1. Classificação dos agentes químicos

\begin{tabular}{lll}
\hline Classificação & Tipo & Descrição \\
\hline $\begin{array}{l}\text { Emprego } \\
\text { tático }\end{array}$ & $\begin{array}{l}\text { causadores de } \\
\text { baixas } \\
\text { inquietantes }\end{array}$ & causam a morte ou lesões permanentes \\
& incapacitantes & causam irritação sensorial \\
\hline $\begin{array}{l}\text { Emprego } \\
\text { fisiológico }\end{array}$ & neurotóxicos & atuam sobre o sistema nervoso \\
& vesicantes & $\begin{array}{l}\text { causam queimaduras químicas por } \\
\text { contato }\end{array}$ \\
& hemotóxicos & $\begin{array}{l}\text { interferem com o processo de } \\
\text { respiração celular }\end{array}$ \\
& sufocantes & atuam sobre o sistema respiratório \\
& vomitivos & $\begin{array}{l}\text { causam irritação das vias aéreas } \\
\text { superiores }\end{array}$ \\
& causam irritação às mucosas dos olhos \\
& psicoquímicos & atuam sobre as funções mentais \\
\hline Persistência & persistentes & $\begin{array}{l}\text { persistem no ambiente por longos } \\
\text { períodos }\end{array}$ \\
& dispersam rapidamente \\
\hline
\end{tabular}

A persistência também é considerada um fator de classificação. A maioria dos agentes químicos militares, incluindo os neurotóxicos, é líquida à temperatura ambiente (apesar de serem conhecidos como gases de guerra) e sua volatilidade determina sua forma de emprego. Agentes muito voláteis são considerados não persistentes, sendo este tipo de substância empregada quando se quer ocupar uma área logo após ter ocorrido um ataque químico. Já os agentes persistentes são aqueles que apresentam uma baixa volatilidade e, dependendo das condições ambientais, podem permanecer depositados na forma líquida por longos períodos de tempo. Esta deposição inviabiliza o uso de uma determinada área e contamina outras, uma vez que os resíduos podem ser transportados para áreas não contaminadas em calçados, viaturas e vestimentas. O VX e as mostardas de enxofre são exemplos de agentes persistentes. ${ }^{5}$

\section{EMPREGO}

Apesar do grande número de substâncias tóxicas conhecidas, somente poucas são adequadas ao uso como agentes químicos de guerra. Muitas delas foram empregadas, mas apenas algumas apresentam os requisitos bélicos necessários, a saber: alta toxicidade; estabilidade química; baixa corrosividade; resistência ao calor liberado no processo de dispersão; resistência à degradação por fatores externos (ambientais); baixo custo e fácil manufatura.

$\mathrm{O}$ agente a ser usado e sua forma de emprego dependerá sempre do objetivo a ser atingido. O processo de dispersão vaporizará parte do agente (nuvem primária) enquanto que o restante será espalhado na forma de gotas. As gotas maiores caem, ficando depositadas no solo e na vegetação (podendo evaporar posteriormente, formando a chamada nuvem secundária), enquanto as gotas menores permanecem dispersas na atmosfera em forma de aerossóis. ${ }^{27}$

\section{AGENTES NEUROTÓXICOS}

\section{Agentes de guerra ${ }^{10}$}

O primeiro organofosforado (OP) a ser sintetizado foi o tetraetilpirofosfato (TEPP), em 1854. Apesar dos avanços subsequentes na química desses compostos, seu potencial tóxico não foi explorado até o século seguinte.

No final da década de 30, um cientista alemão, Gerhard Schraeder, ao pesquisar inseticidas com base em uma estrutura organofosforada, chegou ao tabun (o-etil-N,N-dimetil-fosforamido-cianidato). Porém, devido à sua alta letalidade para os mamíferos, seu uso como inseticida foi descartado. Nesta mesma época, Schraeder também sintetizou o $o$-isopropil- metil-fosfono-fluoridato, que mais tarde seria denominado sarin. A alta toxicidade desta substância levou-a, da mesma forma que no caso do seu antecessor, a ter seu emprego como inseticida também descartado. No entanto, os militares alemães tiveram os interesses despertados para estas substâncias como armas químicas e iniciaram sua produção e acondicionamento em munições. Em 1944, Richard Kuhn sintetizou o o-pinacolil-metil-fosfono-fluoridato (soman). Ao final da Segunda Guerra Mundial, os alemães tinham grandes estoques dos agentes tabun e sarin. Foram estimados estoques entre 10.000 a $30.000 \mathrm{t}$ de tabun e menores quantidades de sarin, todos destinados a uso militar. O soman não foi produzido em larga escala, já que sua descoberta ocorreu pouco antes do final da guerra. Apesar deste arsenal químico e dos aliados não terem conhecimento dos antídotos contra tais agentes, os mesmos nunca chegaram a ser empregados pelos alemães. Após o fim da guerra, a captura de munições, instalações de produção e cientistas alemães pelos aliados, deu-se origem à pesquisa nessa área em outros países. A OTAN atribuiu os seguintes códigos de identificação aos agentes químicos: GA (tabun), GB (sarin), GD (soman).

No início da década de 50, em função de pesquisas sobre inseticidas, na Inglaterra foi sintetizada uma nova classe de neurotóxicos, com destaque para o $o$-etil-S-[2-(di-isopropilamino)-etil]-metil-fosfonotioato (VX - código OTAN).

Os quatro agentes, GA, GB, GD e VX (Figura 1), devido às suas características, foram padronizados para uso em munição química e estocados em grandes quantidades por vários países. Os maiores

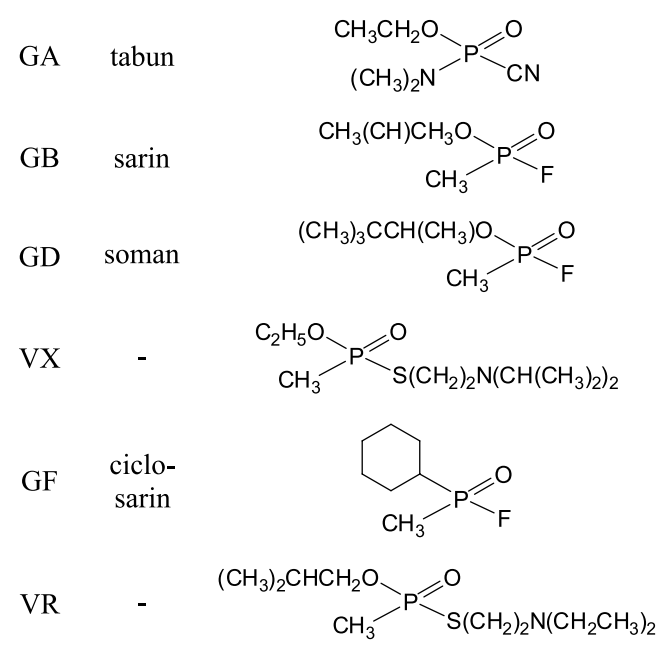

Figura 1. Principais agentes neurotóxicos: nomenclatura da OTAN, nome comum e estrutura química 
Tabela 2. Propriedades físicas dos agentes neurotóxicos

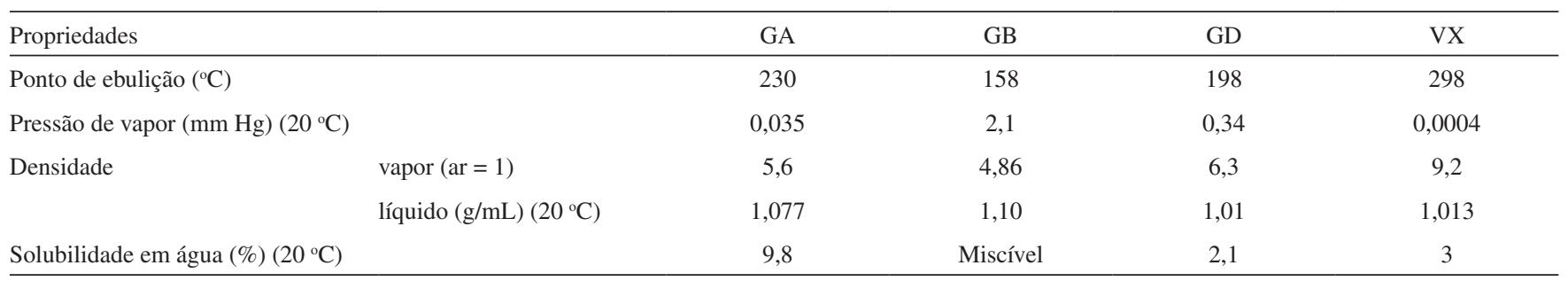

Fonte: ref. 10

estoques foram mantidos pelos EUA (GB e VX) e a antiga URSS (GD e VX), sendo o GA (tabun) geralmente descartado pelas grandes potências por ser o menos tóxico. Por outro lado, sua síntese mais simples o tornou atraente para países menos avançados que queriam se iniciar na área. Isto faz com que eles sejam os principais agentes neurotóxicos estudados na pesquisa em Defesa Química.

Além deles, houve registros de um outro agente neurotóxico, designado GF ou ciclo-sarin (o-ciclo-hexil-metil-fosfonofluoridato), muito similar ao predecessor sarin. Este agente teria sido descartado pelos Estados Unidos pela falta de interesse militar e teria sido supostamente fabricado pelo Iraque durante a Guerra do Golfo. O VR ou VX-russo (o-isobutil S-[2-(dietilamina)etil]-metil-fosfonotioato) seria um análogo russo ao VX. Todas as estruturas citadas estão dispostas na Figura 1.

\section{Propriedades físico-químicas}

Todos os agentes químicos são líquidos incolores à temperatura ambiente, empregados na forma de aerossol a partir da arrebentação da munição que os possui ou por aspergimento.

A série $\mathrm{G}$, devido à sua moderada volatilidade, tem como sua principal rota de absorção a inalação, enquanto o VX, por ser um agente de menor volatilidade é de caráter persistente e sua absorção ocorre através de permeação da pele como a principal rota. Estas características podem ser vistas com mais clareza na Tabela 2, onde faz-se uma comparação de parâmetros físico-químicos importantes para o emprego tático, tais como ponto de ebulição, pressão de vapor e densidade..$^{10}$

Todos os agentes neurotóxicos possuem um átomo de fósforo quiral, o que gera um par de isômeros óticos em proporções iguais. O soman, por possuir também um carbono oticamente ativo no grupamento pinacolil, dá origem a mais dois pares de enantiômeros. Estes estereoisômeros podem ou não diferirem entre eles na velocidade com que reagem com a $\mathrm{AChE}$, não havendo uma regra pré-definida. ${ }^{28}$

O rompimento da ligação P-F por ataque nucleofílico rege a química do soman e do sarin. Para tal rompimento ocorrer, não são necessárias condições enérgicas. O processo se dá em condições brandas e vários nucleófilos cumprem este papel. Por outro lado, quando se envolve o grupamento éster, as reações com nucleófilos ocorrem em condições mais extremas de $\mathrm{pH}$ e temperatura. Para o tabun e para o VX, a ruptura das ligações do fósforo com os respectivos grupos de saída varia com os reagentes nucleofílicos e as condições de reação.

A base da toxicidade dos agentes neurotóxicos consiste no ataque nucleofílico pelo resíduo serina do sítio ativo da acetilcolinesterase, que provoca a cisão das ligações $\mathrm{P}-\mathrm{X}$ com o desprendimento dos grupos de saída $(\mathrm{X}) \cdot{ }^{29}$

\section{Toxicidade}

A Tabela 3 apresenta a toxicidade estimada dos agentes neurotóxicos em seres humanos comparados aos do cianeto de hidrogênio. Nesta tabela nota-se que a exposição letal média, $\mathrm{LCt}_{50}$, que corresponde à concentração do agente no ar pelo tempo de exposição, é muito menor do que a de um reagente considerado altamente tóxico, o cianeto de hidrogênio, comumente usado na indústria química. ${ }^{10}$

Tabela 3. Toxicidade estimada dos agentes neurotóxicos para seres humanos

\begin{tabular}{ccc}
\hline Agente & $\begin{array}{c}\mathrm{LCt}_{50}(\text { inalação }) \\
\left(\mathrm{mg} \mathrm{min} / \mathrm{m}^{3}\right)\end{array}$ & $\begin{array}{c}\mathrm{LD}_{50}(\text { pele }) \\
(\mathrm{mg})\end{array}$ \\
\hline Tabun (GA) & 400 & 1000 \\
Sarin (GB) & 100 & 1700 \\
Soman (GD) & 50 & 350 \\
VX & 10 & $6-10$ \\
Cianeto de hidrogênio & $2500-5000$ & - \\
\hline
\end{tabular}

Fonte: ref. 10

\section{Agroquímicos}

Os organofosforados também constituem a classe de compostos mais empregada como agroquímicos. São produtos químicos utilizados no meio rural para reduzir as perdas de produtividade causadas principalmente pelo ataque de pragas, doenças e plantas daninhas. ${ }^{30}$ Na Figura 2 destacam-se dois exemplos usuais destes compostos: o paraoxon (dietil- $p$-nitrofenil-fosfato) e o metil-paraoxon (dimetil- $p$ -nitrofenil-fosfato). Ressalta-se que, apesar da grande similaridade das estruturas, a toxidez aos mamíferos é menor quando comparada aos agentes químicos neurotóxicos destinados ao uso militar.

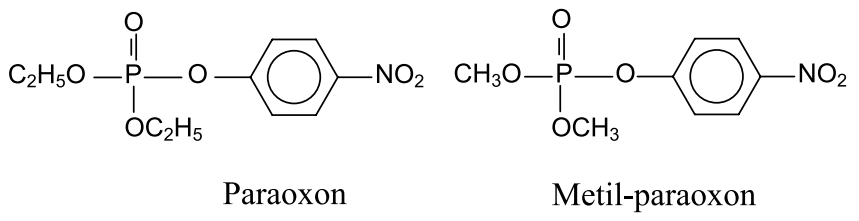

Figura 2. Exemplos de organofosforados utilizados como agroquímicos

Estima-se que a exposição acidental a agroquímicos organofosforados seja de cerca de um milhão de casos anuais, sendo a maior ocorrência em países subdesenvolvidos. ${ }^{12}$ Mesmo assim, só nos Estados Unidos, The American Association of Poison Control Centers' National Incidence Report indica que vítimas de pesticidas em território norte-americano chegam a 80.000 anualmente, sendo que $3,9 \%$ devido a inseticidas. ${ }^{31} \mathrm{~A}$ taxa de mortalidade mundial pode chegar até a $25 \%$ das vítimas de exposição. Internacionalmente, o envenenamento por pesticidas organofosforados chega a ser a forma mais comum de suícidio em alguns países como, por exemplo, no Sri Lanka. ${ }^{31,32}$ Um estudo realizado em Perth, oeste australiano, tomando como base os anos de 1987 a 1996, constatou que homens entre 30 e 50 anos eram mais propensos ao suicídio por organofosforados e, das 69 pessoas estudadas, 68 eram homens. ${ }^{33}$

Outro estudo revela que, em 190 casos de intoxicação aguda por organofosforados que deram entrada no Hospital Cívico de Ahmedabad, Índia, a faixa etária entre 21 e 30 anos abrangeu o maior 
número deles. A proporção homem:mulher desta pesquisa foi de 2,1:1. Do total dos casos, 67,4\% tiveram a intenção de cometer suicídio, $16,8 \%$ resultaram de exposição ocupacional e somente $15,8 \%$ se deveram a envenenamento acidental. ${ }^{34}$

No Brasil, a ocorrência de intoxicações por pesticidas do grupo dos organofosforados continua alta, apesar de seu uso ter diminuído em relação à década de 80 . Os dados estatísticos dos Centros de Toxicologia de Belo Horizonte, Campinas, Florianópolis, Ribeirão Preto, Londrina e Maringá mostram que de 495 casos de intoxicações ocupacionais, cerca de $34,9 \%$ foram devidos a organofosforados; de 622 casos de tentativas de suicídio, 38,1\% resultaram do uso de compostos deste grupo; de 38 casos de óbitos, $44,7 \%$ foram devidos a organofosforados. ${ }^{35,36}$

\section{A ACETILCOLINESTERASE E SEU MODO DE AÇÃO}

As colinesterases pertencem a uma família de hidrolases de serinas, que faz parte de uma família maior de alfa/beta $(\alpha / \beta)$ hidrolases. $^{37,38}$ As colinesterases se dividem em acetilcolinesterases (AChE) e butirilcolinesterases (BuChE). Cada uma delas tem diferentes especificidades dos seus substratos, e o mesmo acontece com os organofosforados, seus inibidores. ${ }^{39}$

A BuChE é sintetizada no fígado e encontrada no plasma sanguíneo; sua função ainda é desconhecida. A AChE, por sua vez, tem uma importante função no organismo dos mamíferos e outras classes. Tem participação fundamental na transmissão dos impulsos nervosos na fibra colinérgica, sendo também encontrada em outras partes do sistema nervoso e em outros sítios do organismo. Atualmente, já se encontram depositadas no Protein Data Bank as estruturas cristalográficas de várias espécies de $\mathrm{AChE}$, inclusive a humana. ${ }^{40}$

A acetilcolinesterase é a enzima responsável pela hidrólise do neurotransmissor acetilcolina em colina e ácido acético nas fibras colinérgicas do sistema nervoso. A acetilcolina é responsável pela transmissão do impulso nervoso através das sinapses até os receptores (nicotínicos e muscarínicos) e a transmissão se encerra no momento da hidrólise. As fibras colinérgicas são responsáveis pela estimulação de vários órgãos do corpo e dos músculos voluntários e o processo de intoxicação por agentes neuroquímicos ocorre no sistema nervoso central e periférico.

Caso a acetilcolina não seja hidrolisada, ocorrerá um acúmulo nos sítios de transmissão colinérgica, o que levará à superestimulação das estruturas enervadas. Os efeitos dessa acumulação são vários, sendo os mais relevantes convulsões, depressão respiratória, arritmia cardíaca e fraqueza. A letalidade do processo deriva da parada respiratória central (depressão do centro respiratório) ou periférica (paralisia dos músculos respiratórios).

Os organofosforados têm imensa afinidade com a enzima acetilcolinesterase, e uma vez ocorrida a reação, a enzima estará inibida e não conseguirá desempenhar seu papel principal, que é a hidrólise da acetilcolina. Estudos indicam que a síndrome colinérgica ocorre por volta de $50 \%$ de inibição da enzima e a morte a partir dos $90 \% . .^{41,42}$

\section{INIBIÇÃO}

A reação de inibição da AChE por organofosforados apresenta algumas diferenças primordiais quando comparada à hidrólise da acetilcolina: ${ }^{43,44}$ menor influência do grupo de saída e maior estabilidade da estrutura fosforilada da AChE inibida.

Com tais características percebe-se que a estrutura inibida é preferida pela enzima.

A reação de inibição pode ser descrita em três etapas: ${ }^{45}$ 1) formação do complexo de Michaelis reversível entre o agente e a enzima; 2) fosforilação e posterior inativação da enzima, através da substituição nucleofílica do grupo de saída pela hidroxila do resíduo serina do sítio ativo; 3) perda do radical alquila (aging ou envelhecimento) pelo organofosforado. ${ }^{46}$ As etapas da reação de inibição estão descritas na Figura 3.

1) Formação do Complexo de Michaelis

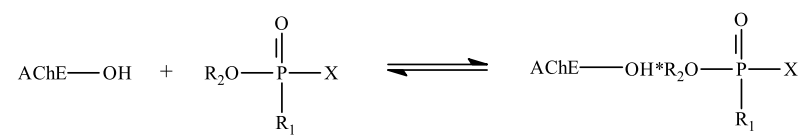

2) Fosforilação da Enzima

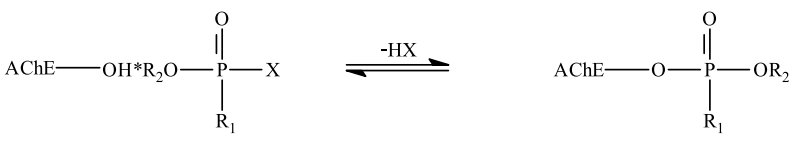

3) "Aging" ou Envelhecimento

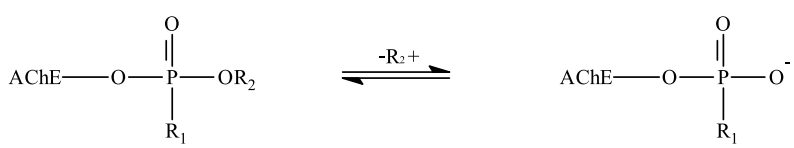

Figura 3. Mecanismo simplificado da inibição da AChE por organofosforados. Adaptada da ref. 43

Como mencionado, a alta estabilidade da estrutura fosforilada formada faz com que esses inibidores sejam confundidos como irreversíveis quando comparados a outros agentes tóxicos, como carbamatos e piretroides. Porém, até a segunda etapa, a reação de reativação da enzima ainda ocorre espontaneamente, mesmo que de forma lenta para ter importância clínica. ${ }^{45}$ A reação irreversível é a que ocorre na última etapa, o aging ou envelhecimento. Dentre os quatro neurotóxicos citados, destaca-se nesta etapa o soman, com tempo de meia-vida de aproximadamente 2 min. Por esta razão, ele é um dos desafios clínicos mais representativos. ${ }^{47}$

Em geral, para possuir uma grande atividade anti-ChE e alta toxicidade aos mamíferos, o organofosforado deve ter a fórmula geral descrita na Figura 4: ${ }^{29}$<smiles>[R]O[PH]([R])([Y])[R]</smiles>

$$
\begin{aligned}
\mathrm{R}_{1}= & \text { alquila ou dialquilamino } \\
\mathrm{R}_{2}= & \text { alquila, cicloalquila, } \\
& \mathrm{H}(\text { (somente na série } \mathrm{V}), \\
& \left.\left(\mathrm{CH}_{2}\right)_{\mathrm{n}} \mathrm{N}^{+} \mathrm{R}_{3} \text { (quando } \mathrm{X}=\mathrm{F}\right) \\
\mathrm{Y}= & \mathrm{O}(\text { raramente } \mathrm{S}) \\
\mathrm{X}= & \mathrm{F}, \mathrm{CN}\left(\text { quando } \mathrm{R}_{1}=\text { dialquilamino), } \mathrm{N}_{3},\right. \\
& \mathrm{S}\left(\mathrm{CH}_{2}\right)_{2} \mathrm{NR}_{2}, \mathrm{~S}\left(\mathrm{CH}_{2}\right)_{2} \mathrm{~N}^{+} \mathrm{R}_{3}, \mathrm{~S}\left(\mathrm{CH}_{2}\right)_{2} \mathrm{~S}^{+} \mathrm{R}_{2}
\end{aligned}
$$

Figura 4. Estrutura geral de alguns organofosforados inibidores de AchE. Adaptada da ref. 26

Quando o grupo de saída $\mathrm{X}$ é do tipo $-\mathrm{OR}_{3}$, onde $\mathrm{R}_{3}$ é alquila ou arila, a toxicidade aos mamíferos diminui. Os agroquímicos organofosforados possuem este grupo, como pode ser visto na Figura 2.

\section{TRATAMENTO}

O tratamento médico da intoxicação por agentes neurotóxicos no campo de batalha se pauta na administração de antídotos específicos que, geralmente, são empregados através de seringas autoinjetoras, administradas pela própria vítima ou por companheiro próximo. Uma sequência de drogas é empregada na seguinte ordem, de acordo com a posologia descrita em diversas referências sobre o assunto: ${ }^{10,27}$

- Atropina: substância anticolinérgica para diminuir os efeitos do acúmulo de acetilcolina nas fibras colinérgicas (Figura 5).

- Diazepam: depressor do sistema nervoso central, agindo para conter os efeitos da síndrome colinérgica, evitando assim convulsões e espasmos musculares (Figura 6). 
<smiles>CN1C2CCC1CC(OC(=O)[C@H](CO)c1ccccc1)C2</smiles>

Figura 5. Atropina<smiles>CN1C(=O)CN=C(c2ccccc2)c2cc(Cl)ccc21</smiles>

Figura 6. Diazepam

- Oxima: reativador da $\mathrm{AChE}$.

Devido à rápida etapa de envelhecimento do complexo $\mathrm{AChE}$ soman, cujo tempo de meia-vida é de 2 min, estas oximas têm seu uso muito restrito contra este agente. Para se ter uma ideia, define-se como fator de proteção (FP) a razão entre as doses letais com e sem administração dos antídotos. Para estudos em condições esperadas de um ataque real por agentes químicos, se considera $\mathrm{FP}=5$ como um valor razoável. Para o soman, os antídotos atingem valores máximos de $\mathrm{FP}=2 .{ }^{10}$

Novas linhas de pesquisa estão sendo desenvolvidas a cada dia na área de defesa química. Tradicionalmente, os EUA e Israel são os países que mais publicam pesquisas sobre esse assunto. Dentre estas linhas de pesquisa destacam-se: ${ }^{48}$

- síntese de novos tipos de oximas, das quais se destacam as denominadas oximas de Hagedorn $(\mathrm{H})$, que têm apresentado resultados melhores que os usuais para os casos de intoxicação por soman. Neste grupo, a oxima com maior número de descrições na literatura é a HI-6 (4-carbamoil-1-[(\{2-[(E)-(hidróxi-imino) metil]piridínio-1-il\}metóxi)metil]piridínio).

- Proteção da AChE através da pré-contaminação por inibidores reversíveis do tipo carbamatos, por exemplo, a fisostigmina ((3aR,8aS)-1,3a,8-trimetil-1H,2H,3H,3aH,8H,8aH-pirrolo[2,3-b] indol-5-il-N-metilcarbamato) e piridostigmina (3-[(dimetilcarbamoil)óxi]-1-metilpiridínio) (Figura 7).<smiles>CNC(=O)Oc1ccc2c(c1)C1(C)CCN(C)C1N2C</smiles>

Fisostigmina

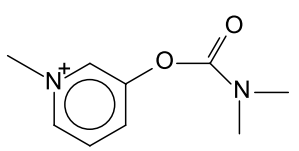

Piridostigmina
Figura 7. Inibidores reversíveis utilizados como pré-tratamento.

- Utilização de scavengers (ou sequestrantes), que seriam diferentes enzimas ou até mesmo a própria $\mathrm{AChE}$, cuja função seria sequestrar o agente neurotóxico antes que ele chegue à $\mathrm{AChE}$ corporal. $\mathrm{O}$ problema desta metodologia é a estequiometria 1:1 entre a AChE e o organofosforado, o que pode levar a um consumo proibitivo dos "sequestrantes". 49

- Utilização de anticorpos específicos.

Apesar das novas técnicas, a utilização de antídotos ainda se faz necessária, em especial as substâncias reativadoras, as oximas. No caso dos scavengers, as oximas são utilizadas como coadjuvantes para melhorar a estequiometria. ${ }^{50,51} \mathrm{~A}$ proteção pelos inibidores reversíveis também só é eficaz com a administração dos antídotos. Além disto, tais métodos estão mais voltados ao ambiente militar. Uma população civil quanto exposta a um ataque químico dificilmente terá acesso às técnicas mais sofisticadas, estando limitada ao tratamento com uso dos antídotos.

As oximas também são empregadas na reativação de colinesterases utilizadas em biossensores de detecção dos agentes químicos, ${ }^{52}$ em equipamentos de descontaminação ${ }^{53} \mathrm{e}$, também, servindo de revestimento, junto à uma matriz polimérica, para roupas de proteção. ${ }^{54}$

\section{REATIVAÇÃO DA ACETILCOLINESTERASE}

Reagentes nucleofílicos adequados são capazes de se combinar com o grupo organofosforado ligado ao resíduo serina do sítio ativo da AChE inibida. Esta estrutura formada, "reativador-OP-AChE", se decompõe em dois produtos, um formado por "reativador-OP" e o outro é a própria AChE regenerada.

Associando um grupo de amônia quaternário, que favorece a reação devido a ligações eletrostáticas no sítio ativo da AChE, a um grupo altamente nucleofílico, como as oximas, em 1955 chegou-se à primeira oxima empregada como reativador da AChE, a 2-PAM..$^{55,56}$

Estudos identificaram uma relação entre a capacidade de reativação e a acidez do grupo oxima. Reativadores em geral apresentam pKa entre 7,0 e 8,0. Esta dependência é explicada pelo fato que oximas ácidas em excesso não seriam bons nucleófilos e oximas pouco ácidas apresentariam uma pequena fração dissociada, que é considerada a forma ativa..$^{57,58} \mathrm{Na}$ Tabela 4 encontram-se alguns reativadores e seus pKa's.

Tabela 4. pKa de reativadores da AChE

Reativador

Fonte: refs. 57 e 58

\section{Estudos experimentais}

A reação de reativação da $\mathrm{AChE}$ depende de vários fatores: da oxima empregada; do inibidor em questão; da espécie na qual a AChE foi obtida e, em alguns casos, do sítio de origem da AChE dentro de uma mesma espécie. ${ }^{59}$

Fora estes fatores, diferentes condições de reação (concentração da oxima, concentração do inibidor, fração da enzima inibida) levam a resultados diferentes, chegando ao ponto de inverter a ordem de eficiência dentro de um dado grupo de oximas. ${ }^{60}$ Não se têm relatos de estudos em seres humanos e, apesar de válidos, estudos com outras espécies são inconclusivos, devido à grande variabilidade entre elas. ${ }^{61}$ Dados experimentais da reativação da TcAChE inibida por agentes de guerra in vitro ${ }^{59}$ podem ser encontrados na Tabela 5. 
Tabela 5. Reativação da TcAChE por diferentes oximas in vitro (\%)

\begin{tabular}{ccccc}
\hline & Tabun & Sarin & Soman & VX \\
\hline 2-PAM & 45 & 23 & 4 & 21 \\
Toxogonina & 43 & 12 & 19 & 40 \\
TMB-4 & 50 & 18 & 18 & 38 \\
HI-6 & 31 & 12 & 35 & 26 \\
\hline
\end{tabular}

Fonte: ref. 59

\section{Estudos teóricos}

O emprego de técnicas de química computacional no estudo de questões relativas a agentes químicos de guerra é especialmente útil como forma de reduzir a necessidade de manipulação destas substâncias em laboratório. ${ }^{62} \mathrm{Na}$ área específica de proteção médica contra a intoxicação por neurotóxicos, os estudos teóricos na área de Defesa Química estão relacionados com a utilização da modelagem molecular, sejam por mecânica molecular ou mecânica quântica, para se entender o efeito causado pelos organofosforados no sítio ativo da AChE, assim como o efeito das diferentes oximas empregadas na desinibição. Os dados obtidos referentes às conformações dos antídotos e aos mecanismos e cinéticas dessas reações permitem um melhor planejamento no desenvolvimento de antídotos novos e mais potentes contra a intoxicação por organofosforados.

No Brasil, o estudo na área de defesa química foi iniciado pelo Exército Brasileiro ${ }^{63}$ em meados da década de 90 , sendo a pesquisa sobre agentes neurotóxicos iniciada com o estudo conformacional por métodos quânticos da molécula de 2-PAM e a construção de um modelo de sítio ativo inibido pelos agentes. ${ }^{64} \mathrm{Na}$ sequência, foi realizado o estudo conformacional da molécula de HI-6 e o estudo da reação de reativação da $\mathrm{AChE}$ inibida por tabun, ambos utilizando também métodos quânticos. ${ }^{65}$

Ainda na linha da modelagem, estudos por dinâmica molecular indicaram que moléculas neutras, ao invés dos sais de amônio quaternário das oximas, teriam mais sucesso na desinibição da AChE. Isto se deve ao fato que, uma vez ocorrida a reativação, é necessário que o composto oxima-organofosforado abandone o sítio ativo nucleofílico o mais rápido possível, evitando a reversibilidade da reação. ${ }^{66}$

Em uma etapa posterior, novamente usando métodos quânticos, outras substâncias foram propostas como potenciais reativadores da $\mathrm{AChE}$ inibida, em vez das tradicionais oximas. Grupos nucleófilos como enolatos, peroxilatos, sulfenatos e hidrazonatos foram estudados. ${ }^{67}$

Apesar do esforço para se buscar alternativas mais eficientes do que as oximas, elas até hoje continuam sendo o principal alvo da química computacional. ${ }^{68,69}$

Seguindo por outro caminho fora do estudo específico da reação de reativação, modelos quânticos também são utilizados para estudar a degradação de agentes de guerra neurotóxicos quando adsorvidos por bases de metais alcalino-terrosos..$^{70,71}$

\section{DESCONTAMINAÇÃO}

Os métodos de descontaminação seguem três mecanismos, basicamente: lavagem com água e sabão, oxidação ou hidrólise básica. A hidrólise ácida é negligível. As mostardas e o VX possuem átomos de enxofre que são facilmente oxidados. Por outro lado, os agentes neurotóxicos da série $\mathrm{G}$ possuem átomos de fósforo em ligações tipo fosfato que são hidrolisados em meio básico.

Tanto a água doce quanto a água salgada removem os contaminantes pela ação mecânica e através da hidrólise lenta. Entretanto, dada a baixa solubilidade e a baixa taxa de hidrólise da maioria dos agentes químicos, os efeitos predominantes da água e sabão são a remoção física e a diluição.

Uma das mais importantes formas de descontaminação é a cloração oxidativa dos agentes por substâncias químicas capazes de liberar cloro quando em solução, por exemplo, hipoclorito. Quanto mais alcalino o pH, maior será a quantidade de cloro livre em solução.

Já a hidrólise alcalina dos organofosforados é iniciada pelo ataque nucleofílico da hidroxila ao átomo de fósforo. Novamente o uso de hipoclorito em meio alcalino é utlilizado para hidrolisar mostardas e VX. Para agentes da classe G lança-se mão de soluções com dietanolamina e hidróxido de sódio. ${ }^{60}$

\section{CONCLUSÕES}

Este trabalho apresentou uma área da química até hoje restrita a poucos países, a Defesa Química. Apesar do crescimento de novas linhas de pesquisa nessa área, os dados disponíveis na literatura científica são poucos devido ao caráter sensível do assunto. Além disso, a maior parte dos dados úteis se encontra em estudos da área médica, e não em bibliografia militar.

Novas tecnologias para fabricação de agentes de querra química como, por exemplo, a utilização de microrreatores de operação contínua controlados por computadores ${ }^{72}$ mostra a importância da continuidade nos estudos.

No Brasil, a atuação nesta área iniciou-se com o Exército Brasileiro na década de 90 . Além disso, este assunto encontra ligação direta com estudos de novos antídotos para casos de intoxicação devido aos agroquímicos.

Atualmente, grupos ligados a este tema no Exército Brasileiro trabalham em parcerias com outras universidades e institutos. Um dos exemplos é a parceria do Grupo de Química Medicinal do Instituto Militar de Engenharia com o Instituto Nacional de Ciência e Tecnologia de Biologia Estrutural e Bioimagem (INBEB) e do Grupo de Físico-química Teórica e Computacional do Instituto Militar de Engenharia com o Grupo de Físico-química de Sólidos e Interfaces da Universidade Federal de Juiz de Fora (UFJF).

\section{REFERÊNCIAS}

1. World Health Organization; Health Aspects of Chemical and Biological Weapons, WHO: Genebra, 1970.

2. Brasil, Ministério do Exército; (C 3-40), 1 a ed., 1987.

3. Venter, A. J.; Janes Intelligence Review 1999, 11, 42.

4. Holstege, C. P.; Kirk, M.; Sidell, F. R.; Crit. Care. Clin. 1997, 13, 923.

5. Castro, A. T.; Rev. Mil. Ciência e Tecnologia 2001, 18, 79.

6. Pangi, R.; BCSIA \& ESDP Discussion Paper, Harvard University: Cambridge, 2002.

7. Prockop, L. D.; J. Neurological Sciences 2006, 249, 50.

8. Sanders, C. A.; Rodigues Jr, M.; Greenbaum, E.; Biosens. Bioeletron. 2001, 16, 439.

9. National Reasearch Council; National Academy Press: Washington, 2003.

10. Sidell, F. R.; Takafuji, E. T.; Franz, D. R.; Medical Aspects of Chemical and Biological Warfare. Textbook of Military Medicine; Office of Surgeon General: Washington, 1997.

11. Dunn, M. A.; Sidell, F. R.; JAMA 1989, 262, 5.

12. World Health Organization; United Nations Environmental Program. Public Health Impact of Pesticides Used in Agriculture, WHO: Genebra, 1990.

13. Farias, R. F.; Neves, L. S.; Silva, D. D.; História da Química no Brasil, $1^{\text {a }}$ ed., Editora Átomo: Campinas, 2004.

14. Dunn, P.; Proc. $4^{\text {th }}$ International Symposium on Protection Against Chemical Warfare, Estocolmo, Suécia, 1992. 
15. Ghanei, M.; Poursaleh, Z.; Harandi, A. A.; Emadi, S. E.; Emadi, S. N.; Cutaneous and Ocular Toxicology Analysis 2009, 2, 679.

16. Chemical Weapons: Threat, Effects and Protection, FOA Briefing Book. Swedish Research Etablishment: Sundbyberg, 1992.

17. Glasby, G. P.; The Science of the Total Environment 1997, 206, 267.

18. Macilwain, C.; Nature 1993, 363, 3.

19. Morito, H.; Yanagisawa, N.; Nakajima, T.; Lancet 1995, 346, 290.

20. Tu, A. T.; VI International Symposium on Protection Against Chemical and Biological Warfare, Estocolmo, Suécia, 1998.

21. Okumura, T.; Takasu, N.; Ishimatsu, S.; Ann. Emerg. Med. 1996, 28, 129.

22. Maskawa, K.; V International Symposium on Protection Against Chemical and Biological Warfare, Estocolmo, Suécia, 1995.

23. Schafer, S. M.; Indianapolis Star, A3, Indianapolis, USA, 1996.

24. Ruane, M. E.; Indianapolis Star, A22, Indianapolis, USA, 1996.

25. http://www.opcw.org, acessada em Dezembro 2011.

26. Rickett, D. J.; Glenn, J. F.; Houston, W. E.; Military Medicine 1987, 152, 35 .

27. Marrs, T. C.; Maynard, R. L.; Sidell, F. R.; Chemical Warfare Agents: Toxicology and Treatment, John Wiley \& Sons: Chichester, $2^{\text {nd }}$ ed., 2007.

28. Benschop, H. P.; De Jong, L. P. A.; Acc. Chem. Res. 1988, 21, 368.

29. Black, R. M.; Harrison, J. M. Em The Chemistry of Organophosphorus Compounds; Hartley, F. R., ed.; John Wiley \& Sons: Chichester, 1996.

30. http://www.andef.com.br, acessada em Outubro 2011.

31. http://emedicine.medscape.com/article/167726-overview, acessada em Agosto 2012.

32. Yamashita, M.; Yamashita, M.; Tanaka, J.; Vet. Hum. Toxicol.1997, 39, 84.

33. Emerson, G. M.; Gray, N. M.; Jelinek, G. A.; J. Emerg. Med. 1999, 17, 273.

34. Agarwal, S. B.; Environ. Res. 1993, 62, 63.

35. Cavaliere, M. J.; Calore, E. E.; Perez, N. M.; Puga, F .R.; Rev. Saúde Pública 1996, 30, 3.

36. UNICAMP/ANDEF/SINDAG; Relatório do Projeto CCI, Campinas, 1994.

37. Ollis, D. L.; Cheah, E.; Cygler, M.; Dijkstra, B.; Frolow, F.; Franksen, S. M.; Harel, M.; Remington, S. J.; Silman, I.; Schrag, J.; Sussman, J. L.; Verschueren, K. H. G.; Goldman, A. G.; Protein Eng. 1992, 5, 197.

38. Nardini, M.; Dijkstra, B. W.; Curr. Opin. Struct. Biol. 1999, 9, 732.

39. Taylor, P.; Radic, Z.; Ann. Rev. Pharm. Toxicol. 1994, 34, 281.

40. Soreq, H.; Ben-aziz, R.; Prody, C. S.; Seidman, S.; Gnatt, A.; Neville, L.; Lieman-Hurwitz, J.; Lev-Lehman, E.; Ginzberg, D.; Lipidot-Lifson, Y.; Proc. National Acad. Sci. U. S. A. 1990, 87, 9688.

41. Jeyaratnam, J.; Maroni, M.; Toxicology 1994, 91, 15.

42. Moretto, A.; Toxicol. Lett. 1998, 102-103, 509.

43. Bencsura, A.; Enyedy, I. Y.; Kovach, I. M.; J. Am. Chem. Soc. 1996, 118 , 8531.

44. Bencsura, A.; Enyedy, I. Y.; Kovach, I. M.; Biochemistry 1995, 34, 8989.

45. Marrs, T. C.; Maynard, R. L. Em Handbook of Clinical Neurology; Vinken, P. J.; Bruyn, G. W.; De Wolff, F. A., eds.; Elsevier: Amsterdam, 1994.

46. Sidell, F. R.; Borak, J. J.; Annals Emerg. Med.1992, 21, 865.
47. Dunn, M. A.; Hackley Jr, B. E.; Sidell, F. R. Em Medical Aspects of Chemical and Biological Warfare. Textbook of Military Medicine; Sidell, F. R.; Takafuji, E. T.; Franz, D. R., eds.; Office of Surgeon General: Washington, 1997.

48. Somani, S. M.; Solana, R. P.; Dube, S. N. Em Chemical Warfare Agents, Somani, S. M., ed.; Academic Press: London, 1992.

49. Maxwell, D. M.; Doctor, B. P. Em ref. 48.

50. Maxwell, D. M.; Saxena, A.; Gordon, R. K.; Doctor, B. P.; Chemicalbiological Inteactions 1999, 119-120, 419.

51. Caranto, G.; Waibel, K. R.; Asher, J. M.; Biochem. Pharmacol. 1994, $47,347$.

52. Okazaki, S.; Nakagawa, H.; Fukuda, K.; Asakura, S.; Kiuchi, H.; Shigemori, T.; Takahashi, S.; Sens. Actuators, B 2000, 66, 131.

53. Gordon, R. K.; Feaster, S. R.; Russel, A. J.; Lejeune, K. E.; Maxwell, D. M.; Lenz, D. E.; Ross, M.; Doctor, B. P.; Chemical-Biological Interactions 1999, 119-120, 463.

54. Lejeune, K. E.; Dravis, B. C.; Yang, F.; Hetro, A. D.; Doctor, B. P.; Russell, A. J.; Ann. Acad. Sci. 1998, 864, 153.

55. Wilson, I. B.; Ginsburg, S.; Biochim. Biophys. Acta 1955, 18, 168.

56. Childs, A. F.; Davies, D. R.; Green, A. L.; Rutland, J. P.; Brit. J. Pharmacol. Chem.1955, 10, 462.

57. Gray, A. P.; Drug Metab. Reviews 1982, 15, 557.

58. Hagedorn, I.; Stark, I.; Lorenz, H. P.; Angnew Chem., Int. Ed. 1972, 11, 307.

59. Hanke, D. W.; Overton, M. A.; J. Toxicol. Environ. 1991, 34, 141.

60. Harvey, B.; Sellers, D. J.; Watts, P.; Biochem. Pharmacol. 1984, 33, 3499.

61. Dawson, R. M.; J. Appl. Toxicol. 1994, 14, 317.

62. Underhill, P. R.; Defense Stablishment Suffield, Workshop on Alternatives to Animals, Alberta, Canada, 1987.

63. Delfino, R. T.; Ribeiro, T. S.; Figueroa-Villar, J. D.; J. Braz. Chem. Soc. 2009, 20, 407.

64. Castro, A. T.; Figueroa-Villar, J. D.; Int. J. Quantum Chem. 2002, 89, 135; Castro, A. T.; Dissertação de Mestrado, Instituto Militar de Engenharia, Brasil, 2002.

65. Silva, G. R.; Borges Jr., I.; Figueroa-Villar, J. D.; Int. J. Quantum Chem. 2005, 105, 260; Silva, G .R.; Dissertação de Mestrado, Instituto Militar de Engenharia, Brasil, 2005.

66. Gonçalves, A. S.; França, T. C. C.; Silva, A. W. S.; Figueroa-Villar, J. D.; J. Braz. Chem. Soc. 2006, 17, 968.

67. Delfino, R. T.; Figueroa-Villar, J. D.; J. Phys. Chem. B 2009, 113, 8402.

68. Ramalho, T. C.; França, T. C. C.; Rennó, M. N.; Guimarães, A. P.; Cunha, E. F. F.; Kuca, K.; Chemico-Biological Interactions 2010, 187, 436.

69. Guimarães, A. P.; França, T. C. C.; Ramalho, T. C.; Rennó, M. N.; Cunha, E. F. F.; Matos, K. S.; Mancini, D. T.; Kuca, K.; J. Appl. Biomed. 2011, 9, 163.

70. Vaiss, V. S.; Borges Jr., I.; Leitão, A. A.; J. Phys. Chem. C 2011, 115 , 24937.

71. Alvim, R. S.; Dissertação de Mestrado, Universidade Federal de Juiz de Fora, Brasil, 2009.

72. Parshall, G. W.; Pure Appl. Chem. 2002, 74, 2259. 